\title{
Frequent expression of new cancer/testis gene D40/AFI5qI4 in lung cancers of smokers
}

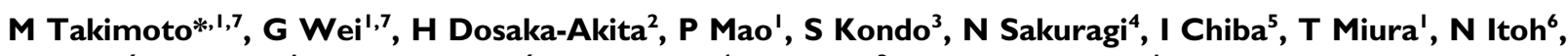 T Sasao', RC Koya', T Tsukamoto ${ }^{6}$, S Fujimoto $^{4}, \mathrm{H}^{6} \mathrm{Katoh}^{3}$ and N Kuzumaki'}

\begin{abstract}
'Division of Cancer Gene Regulation, Research Section of Disease Control, Institute for Genetic Medicine, Hokkaido University, Sapporo, Hokkaido, Japan; ${ }^{2}$ Department of Medical Oncology, Graduate School of Dental Medicine, Hokkaido University, Hokkaido, Japan; ${ }^{3}$ Department of Surgical Oncology, Graduate School of Dental Medicine, Hokkaido University, Hokkaido, Japan; ${ }^{4}$ Department of Obstetrics and Gynecology, Graduate School of Medicine, Graduate School of Dental Medicine, Hokkaido University, Hokkaido, Japan; ${ }^{5}$ Oral Diagnosis and Oral Medicine, Department of Oral Patho-Biological Science, Graduate School of Dental Medicine, Hokkaido University, Hokkaido, Japan; 'Department of Urology, Sapporo Medical University, Sapporo, Hokkaido, Japan
\end{abstract}

We found a significant correlation between lung cancer in smokers and the expression of a human gene, D40, predominantly expressed in testis and cancers. In an attempt to clone a novel human gene, we screened a cDNA library derived from a human B cell line and obtained a cDNA clone that we refer to as D40. A search for public databases for sequence homologies showed that the D40 gene is identical to AFI5qI4. D40 mRNA is predominantly expressed in normal testis tissue. However, this gene is also expressed in various human tumour cell lines and primary tumours derived from various organs and tissues, such as lung cancer. We examined the relationship between D40 expression and clinico-pathological characteristics of tumours in primary lung cancer. D40 expression did not significantly correlate with either histological type or pathological tumour stage. However, D40 expression was observed more frequently in poorly differentiated tumours than in well or moderately differentiated ones. Furthermore, the incidence of D40 expression was significantly higher in tumours from patients who smoke than in those from non-smokers. D40/AFI5qI4 is the first gene in the cancer/testis family for which expression is related to the smoking habits of cancer patients.

British Journal of Cancer (2002) 86, 1757 - 1762. doi:I0.1038/sj.bjc.6600328 www.bjcancer.com

(c) 2002 Cancer Research UK

Keywords: D40; testis; cancer/testis (CT); AFI5q I4; lung cancer; smoking

Tumour cells often express genes that are otherwise expressed in normal cells at very low levels if at all (Bishop, 1987). Such aberrantly expressed genes include proto-oncogenes and those involved in tissue-specific differentiation. The expression of these genes in tumour cells probably contributes to the malignant phenotypes and the recognition of tumour cells by the host immune system (Boon et al, 1997).

The testis, an essential organ of the male reproductive system, produces spermatozoa in which genetic information is stored within the haploid genome (Bloom and Fawcett, 1994). Of the dozens of genes that are expressed in the testis, some are expressed in a testis-specific manner related to spermatogenesis. Whereas most testis-specific genes are either never or very rarely activated in tumours (De Smet et al, 1997), recent studies have identified a class of genes that is expressed both in the normal testis and in cancerous tissue. Some of them elicit an immune response in hosts and are called cancer/testis (CT) antigen (Boon et al, 1997; Chen and Old, 1999). Others, for which the antigenicity remains unknown, are expressed in similar manner to CT. Some of these display sequences homology to $\mathrm{CT}$ and are expressed not only in testes but also in other male and female reproductive organs

\footnotetext{
*Correspondence: M Takimoto; E-mail: takimoto@med.hokudai.ac.jp.

${ }^{7}$ These two authors have contributed equally to this work.

Received 3 December 200I; revised 4 March 2002; accepted 27 March 2002
}

(Brinkmann et al, 1998). Overall, these may all be referred to CT family genes or CT genes. Their potential application in the diagnosis and immunogene therapy of cancer has been extensively studied (Boon et al, 1997; Chen and Old, 1999). However, little is known about either clinico-pathological features of their expression in tumours or their physiological functions. This information is very important in characterisation of CT genes and when considering immunotherapy with these genes. Understanding the clinicopathological characteristics of their expression would facilitate determination of which CT gene product should be selected as tumour targets for therapy.

In this study, we report on a human gene, D40, that is primarily expressed in normal testis tissues. Initially, we searched for proteins that interact with the transcription factor GCF using the yeast twohybrid system (Kageyama and Pastan, 1989; Chien et al, 1991). After we obtained a cDNA clone, D40, that binds to GCF, we later discovered that the reported GCF cDNA clone is chimeric, consisting of two different cDNA fragments. One was derived from the GCF2 transcription factor and the other was from unrelated gene product with unknown function (Reed et al, 1998; Takimoto et $a l, 1999)$. D40 protein binds to the latter. A sequence homology search revealed that D40 is the same gene as AF15q14 which was recently identified as one of the genes that fuses with an oncogenic gene MLL (mixed lineage leukaemia) in acute leukaemia (Hayette et al, 2000). While the D40 gene is barely expressed in normal tissues except for the testis, it is expressed frequently in various human cancer cell lines and primary tumours derived from differ- 
ent tissues and organs, suggesting that D40 is a novel member of the CT family. Furthermore, the incidence of D40 expression is significantly higher in poorly differentiated primary lung cancer and in cancers from patients with a smoking habit. To our knowledge, D40/AF15q14 is the first gene in the CT family for which expression is significantly related to smoking habits of the patients with cancer.

\section{MATERIALS AND METHODS}

\section{Cultured cell lines, tumour samples, and patients}

Cell lines used in this study are described in Table 1. The cultured cells were maintained in RPMI 1640 or DMEM with $10 \%$ foetal calf serum and $0.3 \mathrm{mg} \mathrm{ml}^{-1}$ L-glutamine. Cells were cultured at $37^{\circ} \mathrm{C}$ in a $5 \% \mathrm{CO}_{2}$ atmosphere. Primary tumour samples obtained from surgical operations were quickly frozen in liquid nitrogen and stored at $-80^{\circ} \mathrm{C}$ until RNA isolation. Experiments on surgical samples were performed after obtaining written informed consent from the patients. Sections of tumour specimens were reviewed by pathologists. Lung tumour specimens were histopathologically diagnosed according to the 1981 World Health Organization classification (WHO, 1982). The postsurgical pTMN stage was determined according to the guidelines of the American Joint Committee on Cancer (Bearhs et al, 1992). Smokers analysed in this study were current smokers, including individuals who stopped smoking 3 months before surgery. Non-smokers were those who had never smoked.

\section{cDNA cloning and DNA sequencing of D40}

The carboxy terminal two-thirds of the coding region of the previously described transcription factor GCF (Kageyama and Pastan, 1989) was subcloned into pGBT-9 (Clontech) and the resultant plasmid was used in yeast two-hybrid screening with the yeast strain Y153 and a cDNA library of a human B cell line (Fields and Song, 1989; Chien et al, 1991; Durfee et al, 1993). Out of 1.2 million yeast clones screened, nine were positive for both histidine and LacZ phenotypes. After confirming that one of the clones possessed binding specificity, we determined the nucleotide sequences. We screened a cDNA library from a human promyelocytic leukaemia HL60 cell line for longer clones using this

Table I Human cancer cell lines that express D40 mRNA

\begin{tabular}{ll}
\hline Cell type & Name of cell line \\
\hline Lung cancer & PIIO \\
& NCIH226 \\
& RERF-LC-MS \\
& RERF-LC-OK \\
Melanoma & SKMEL \\
& AKI \\
Bladder cancer & G36I \\
& DAB-I \\
& T-24 \\
Cervical cancer & UMUC-2 \\
Epidermoid cancer & HeLa \\
Breast cancer & A43I \\
T-cell lymphoma & MCF-7 \\
Promyelocytic leukaemia & Jurkat \\
Oral squamous cancer & HL60 \\
Oesophageal cancer & HSC-2 \\
Pancreatic cancer & TE-8 \\
\hline
\end{tabular}

Total RNA from human cell lines were tested by RT - PCR assay for the expression of D40 as described in Materials and methods section. D40 expression was observed in all of the cancer cell lines examined. Representative results on RT - PCR analysis are shown in Figure 2. clone. Rapid amplification of cDNA ends (RACE) (Frohman et al, 1988) was performed with the D40-specific primers and the protocol provided with a commercial 5'/3' RACE kit (Boehringer/ Roche). For DNA sequencing, plasmid DNAs prepared with a commercial column (Qiagen) served as templates in cycle sequencing reactions performed using dideoxy chain termination (Sanger et al, 1977) Sequence were analysed using fluorescence DNA sequencers. Public databases on the Internet were searched for sequence homology.

\section{RNA isolation}

Total RNA from cell lines and tumour samples was isolated and purified by the acid-guanidinium-phenol chloroform method (Chomczynski and Sacchi, 1987). Approximately $1 \times 10^{7}$ cells or $80 \mathrm{mg}$ of tumour tissues were homogenised in $2 \mathrm{ml}$ of Trizol reagent (Life Technology) to purify the RNA.

\section{Northern blot analyses}

Northern blot analyses were performed as described (Sambrook et $a l, 1989)$. Probe DNAs were radiolabelled with $\alpha-{ }^{32} \mathrm{P}-\mathrm{dCTP}$ using a commercial random priming kit (Takara, Kyoto, Japan). Hybridisation proceeded in $50 \%$ formamide, $5 \times$ SSC, $5 \times$ Denhardt's solution and $0.5 \%$ SDS at $37^{\circ} \mathrm{C}$ overnight. Blotted membranes were then washed at progressively higher stringency. The membranes were finally washed in $0.2 \times$ SSC containing $0.1 \%$ SDS at $48^{\circ} \mathrm{C}$. Signals were detected using a BAS2000 (Fuji Film, Tokyo, Japan).

\section{Reverse transcription polymerase chain reaction (RT - PCR)}

Total RNA $(1 \mu \mathrm{g})$ was reverse-transcribed to cDNA with a reverse primer, MT152 (5'- TCCCATCTTCTGATGTG-3'), and Superscript II RNase $\mathrm{H}^{-}$reverse transcriptase (Life Technology). Amplification was performed with $0.1 \mu \mathrm{g}$ cDNA, 10 pmol of D40-specific oligonucleotides (forward: MT149; 5'-CACATCCAGTGAGACCA-3', reverse: MT152), and 0.5 units of Taq polymerase in a total reaction volume of $20 \mu \mathrm{l}$ with a buffer containing $10 \mathrm{mM}$ Tris- $\mathrm{HCl}$, $1.5 \mathrm{mM} \mathrm{MgCl}_{2}$, and $50 \mathrm{mM} \mathrm{KCl}, \mathrm{pH}$ 8.3. Primers for $\beta$-actin were used in the amplification to check the RNA integrity.

\section{Statistical analysis}

Associations between D40 expression and categorical variables were analysed by the $\chi^{2}$ test or Fisher's extract test as appropriate (Mehta and Patel, 1983). Associations between D40 expression and age were analysed by the Student's $t$-test. The significance level was $P<0.05$ and all tests were two-sided.

\section{RESULTS}

\section{Identification and cloning of the human gene D40}

In an attempt to clone a novel human gene, we performed twohybrid screening of the cDNA library derived from a human B cell line using the transcription factor GCF (Kageyama and Pastan, 1989) as bait and were able to obtain a cDNA clone that we called D40. DNA sequencing analyses revealed that the clone had an open reading frame. Using a part of the clone as a probe, a cDNA library from a human leukaemia cell line was screened to obtain longer clones. During the course of cloning, we noticed that the initial D40 clone had a deletion of a nucleotide in the middle of the coding region that leads to an occurrence of a stop codon several bases downstream of the deletion (Takimoto, 1999). As none of the other clones had in-frame stop codons at both ends, we performed rapid amplification of cDNA ends (RACE). We were able to find the clones that had an in-frame stop codon in the $5^{\prime}$ end and those 
in the $3^{\prime}$ end with $5^{\prime}$ and $3^{\prime}$ RACE analyses, respectively; we called this gene D40. In the later stage of this study, however, it turned out that the sequence of D40 is identical with that of the gene AF15q14 (Hayette et al, 2000), except for the $3^{\prime}$ end and several nucleotides. The nucleotide sequence in D40 cDNA revealed in this study was deposited in GenBank/EMBL/DDBJ (accession no: AB022190).

\section{Expression of D40 mRNA is abundant in testis tissue but not in other normal human tissues}

The expression of the D40 gene in various normal human tissues was examined. Northern hybridisations were performed on membranes on which multiple human tissue mRNA samples were blotted as described in the Materials and methods section. The results revealed that a high level of D40 mRNA expression was observed in testis tissue and a lower level of expression was detected in placenta tissue. A major transcript of about 8.5 kilo base $(\mathrm{kb})$ and a minor one of about $7 \mathrm{~kb}$ in size were detected in the testis tissue. However, D40 expression was not significant in any other normal tissues (Figure 1). With longer exposure of the Northern blot, slight D40 expression was observed in a few tissues, far below that in testis tissue (data not shown). These results indicate that the D40 mRNA is dominantly expressed in testis tissue.

\section{The D40 gene is expressed in various human cancer cell lines and primary tumours}

We also observed D40 expression in several tumour cell lines as well as in normal testis tissue. We next examined the mRNA expression of D40 in various human cancers. When we examined D40 expression in different human cancer cell lines, we found that D40 was expressed in the cell lines of four lung cancers, three melanomas, three bladder cancers, one cervical cancer, one epidermoid cancer, one breast cancer, one lymphoma, one leukaemia and tumours derived from the alimentary tract (Table 1). Typical experimental results are shown in Figure 2.

We then examined D40 expression in human primary tumours. Total RNAs were prepared from frozen samples of human primary tumours obtained from surgical operations. Analyses by the RTPCR assay on different primary tumours had detected D40 transcripts in significant fractions of primary tumour samples, such as lung cancer, ovary cancer and pancreatic cancer. Typical results of RT-PCR analyses on the primary tumours are shown in Figure
3. Out of 46 cases of primary lung cancer examined, D40 expression was observed in 19 cases (more than 40\%). Several other primary cancers also showed D40 expression with comparable or lower frequencies depending on the types of tumours, such as ovary cancer, $36 \%$; pancreatic cancer, $27 \%$; and cervical cancer, $38 \%$ (Table 2). These results indicate that the D40 gene is expressed in different human cancers.

\section{Frequent expression of the D40 gene in poorly differentiated lung tumours and in tumours of smokers}

To characterise D40 expression in human primary tumours, lung cancer was chosen in which to examine the potential correlation between D40 expression and clinico-pathological characteristics. The expression of D40 in 46 cases of primary lung cancer was examined in comparison with several characteristic items and the examinations were processed with statistical methods. The results showed that D40 expression has no relation to a patient's age or sex, or to a tumour's histology and pathological stages, such as tumour size and lymph node metastasis. However, the incidence of D40 expression was significantly higher in poorly differentiated tumours than well or moderately differentiated ones $(P<0.04)$. Further, significantly higher incidence of D40 expression was observed in primary lung tumours from patients with smoking habits compared with tumours from non-smokers $(P<0.02)$ (Table 3).

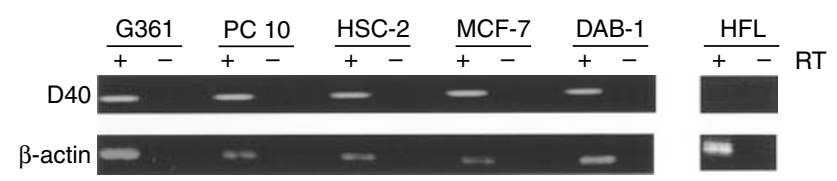

Figure 2 Expression of the D40 gene in human cancer cell lines analysed by the RT $-P C R$ assay. To isolate and purify total RNA, about $I \times 10^{7}$ cells of each human cancer cell line were homogenised in $2 \mathrm{ml}$ of Trizol reagent. The RT-PCR assay was performed on the purified RNA as described in the Materials and methods section. Typical results of RT-PCR analyses on D40 expressions in cancer cell lines are shown: G36I (melanoma), PCIO (lung cancer), HSC-2 (oral cancer), MCF-7 (breast cancer), DAB-I (bladder cancer), HFL (normal fibroblast of lung). RT + or - indicates with or without reverse transcription. The results of $\beta$-actin RT-PCR analyses indicate that the RNA integrity was maintained in all samples.

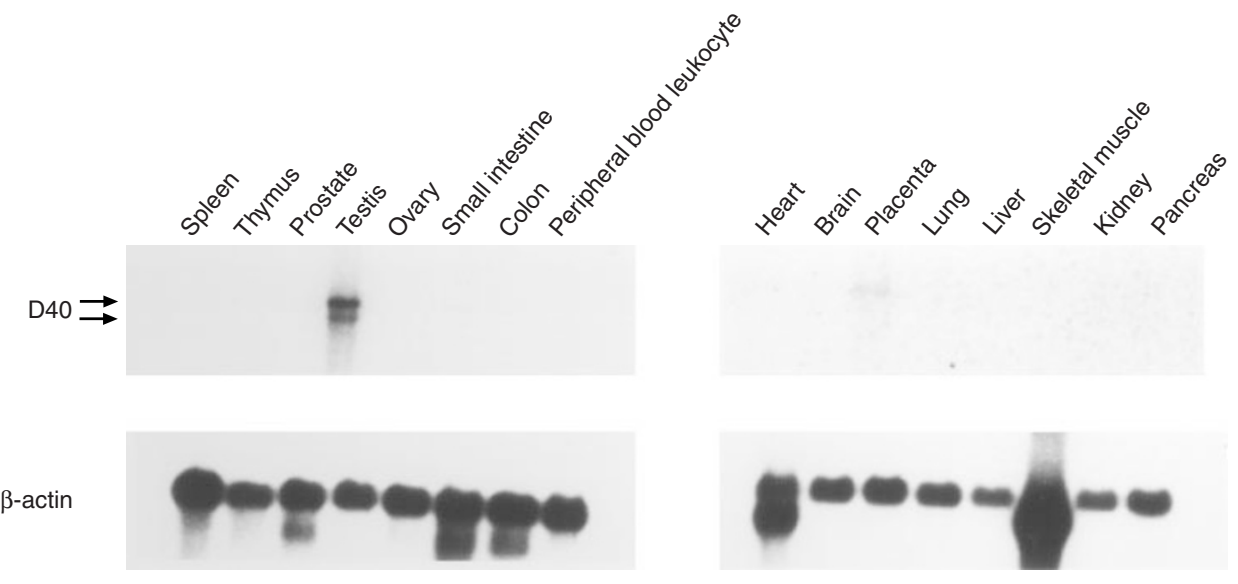

Figure I Northern blot analyses of D40 expression in normal human tissues. Northern hybridisations were performed on membranes on which multiple human tissue mRNA samples were blotted as described in the Materials and methods section. Expression of D40 mRNA was observed in the testis tissue sample but not in other normal tissues, except for the placenta sample, which showed trace expression. Arrows indicate the transcripts, 8.5 and $7 \mathrm{~kb}$ in length (upper). The membranes were stripped of D40 probe, then rehybridised with $\beta$-actin probe to confirm RNA integrity on the membrane (lower). 
Table 2 Expression of D40 mRNA in human primary tumours

\begin{tabular}{lcc}
\hline Tumour type & Positive sample/total sample & (\% positive) \\
\hline Lung cancer & $19 / 46$ & $(41 \%)$ \\
Ovary cancer & $4 / 11$ & $(36 \%)$ \\
Pancreatic cancer & $3 / I 1$ & $(27 \%)$ \\
Cervical cancer & $3 / 8$ & $(38 \%)$ \\
Colon cancer & $1 / 8$ & $(13 \%)$ \\
Glioblastoma & $1 / 5$ & $(20 \%)$ \\
Cholangiocarcinoma & $0 / 7$ & $(0 \%)$ \\
Stomach cancer & $0 / 4$ & $(0 \%)$ \\
Seminoma & $0 / 3$ & $(0 \%)$ \\
\hline
\end{tabular}

Human primary tumours were examined in the expression of D40 by the RT-PCR assay as described in Materials and methods section. The presence of amplification products in agarose gel is regarded as positive result. Numbers in parenthesis are the percentages of positive sample.

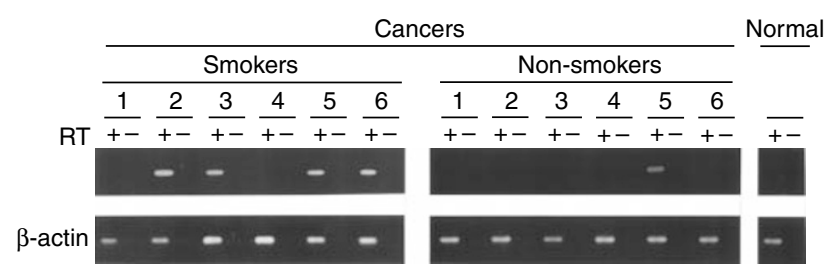

Figure 3 Expression of D40 mRNA in primary human cancer assayed by RT-PCR. Typical experimental results of RT-PCR analyses of D40 expression in primary cancer. D40 mRNA expression was analysed in total RNA from primary lung tumours and from normal lung as described in the Materials and methods. Numbers are individual primary lung tumours from smokers and non-smokers. RT + or - indicates with or without reverse transcription. Levels of $\beta$-actin in same RNAs were analysed by RT PCR to confirm sample integrity.

Table 3 Relationship between D40 expression and clinical and clinicopathological characteristics in 46 cases of lung cancers

\begin{tabular}{|c|c|c|c|}
\hline \multirow[b]{2}{*}{ Characteristics } & \multicolumn{2}{|c|}{ D40 expression } & \multirow[b]{2}{*}{$P$} \\
\hline & $(-)$ & $(+)$ & \\
\hline Age (mean+s.d.) & $63.8 \pm 11.5$ & $64.7 \pm 12.5$ & $N S^{\mathrm{a}}$ \\
\hline Sex & & & \\
\hline $\begin{array}{l}\text { Male } \\
\text { Female }\end{array}$ & $\begin{array}{c}18 \\
9\end{array}$ & $\begin{array}{c}15 \\
4\end{array}$ & NS \\
\hline $\begin{array}{l}\text { Smoking } \\
\text { Non-smoker } \\
\text { Smoker }\end{array}$ & $\begin{array}{l}10 \\
17\end{array}$ & $\begin{array}{c}1 \\
18\end{array}$ & 0.02 \\
\hline $\begin{array}{l}\text { Histology } \\
\text { Squamous } \\
\text { Adeno } \\
\text { Large cell } \\
\text { Small cell }\end{array}$ & $\begin{array}{c}9 \\
18 \\
0 \\
0\end{array}$ & $\begin{array}{c}4 \\
10 \\
3 \\
2\end{array}$ & NS \\
\hline $\begin{array}{l}\text { Differentiation } \\
\text { Well and moderate } \\
\text { Poor }\end{array}$ & $\begin{array}{c}19 \\
8\end{array}$ & $\begin{array}{c}7 \\
12\end{array}$ & 0.04 \\
\hline $\begin{array}{l}\text { pT classification } \\
\quad \begin{array}{l}\text { c } \\
2-4\end{array}\end{array}$ & $\begin{array}{c}7 \\
20\end{array}$ & $\begin{array}{c}2 \\
15\end{array}$ & NS \\
\hline $\begin{array}{l}\text { pN classification } \\
0 \\
1-3\end{array}$ & $\begin{array}{l}12 \\
15\end{array}$ & $\begin{array}{l}8 \\
9\end{array}$ & NS \\
\hline
\end{tabular}

${ }^{a} \mathrm{NS}$, not statistically significant. ${ }^{\mathrm{b}} \mathrm{Squamous}$, squamous cell carcinoma; adeno, adenocarcinoma; large cell, large cell carcinoma; small cell, small cell carcinoma. ${ }^{c} \mathrm{pT}$ and pN classifications are only for squamous cell carcinomas, adenocarcinomas and large cell carcinomas.

\section{DISCUSSION}

In this study, we identified human gene D40 that is predominantly expressed in the normal testis tissue, but not in other normal tissues. A sequence homology search revealed that the D40 sequence is the same as that of the AF15q14 gene (Hayette et al, 2000). This gene is a partner that fuses with MLL, an oncogenic gene involved in the development of acute leukaemia (Hunger et al, 1993; Thirman et al, 1994; Hernandez et al, 1995; Dimartino and Cleary, 1999). In contrast to normal tissues, D40 was expressed in all human cancer cell lines examined and in several primary human tumours independently of the types and source of the tumours. The incidence of D40 expression was significantly higher in tumours derived from smokers as well as in poorly differentiated tumours.

Most testis-specific genes are either never or very rarely activated in tumours (De Smet et al, 1997). However, recent studies, have disclosed a class of genes that is expressed both in the normal testis tissue and in cancer. They are referred as cancer/testis (CT) genes or CT family genes. The expression profile of the D40 gene resembles that of CT genes, suggesting that D40 is also a member of this family. Some of the CT genes elicit immune response in patients with malignancies and these are called CT antigens, constituting several subfamilies of genes, such as MAGE (melanoma antigen) (Van der Bruggen et al, 1991; Boon et al, 1997; Chen and Old, 1999). They were originally identified as tumour antigens recognised by cytotoxic $\mathrm{T}$ lymphocytes or by antibodies in the sera of patients with cancer (Sahin et al, 1995; Boon et al, 1997; Chen and Old, 1999). Further study is needed to determine whether D40 protein elicits immune responses in patients with cancer.

Very few reports have described the relationship between the CT gene and clinico-pathological characteristic, The size of a primary hepatocellular carcinoma is reportedly larger and the serum $\alpha$-fetoprotein level is reportedly lower in MAGE-positive than in MAGEnegative patients (Suzuki et al, 1999). To our knowledge, no one has reported that expression of a CT gene is significantly correlated to the smoking habits of patients, as this study revealed.

We questioned why a gene expressed in the testis in a restricted manner would be expressed frequently in different human tumours. A clue might be found in the experimental data from primary lung cancer indicating that poorly differentiated tumours and tumours from smokers express D40 at high frequency. Tobacco smoke contains a mixture of highly mutagenic chemicals, such as benzo(a)pyrene and 4-methylnitrosoamine-1-(3-pyridyl)-1-butanone. Benzo(a)pyrene induces point mutations such as $G$ to $T$ transversion (Ruggeri et al, 1993) and forms DNA adducts at the major mutational hot spots of the p53 gene in lung cancer (Denissenko et al, 1996). The mutagen 4-methylnitrosoamine-1-(3pyridyl)-1-butanone causes epigenetic alterations of the genome through the modification of DNA methyltransferase activity (Belinsky et al, 1996). Cellular genes, including D40, which are barely expressed in normal cells, may be dysregulated so that they are expressed abnormally when exposed to these chemicals in tobacco smoke. Compared with well-differentiated lung tumours, poorly differentiated tumours may be more deviated from the normal state in gene regulation. The poorly differentiated tumour cells may arise through the accumulation of dysregulated gene expressions affected by mutagenic chemicals in tobacco smoke.

In contrast to D40, expression of the actin regulatory protein, gelsolin, is significantly reduced in primary lung tumours of patients with a smoking habit (Dosaka-Akita et al, 1998). Expression of the tumour suppressor p16 (INK4a) gene is often suppressed in tumour cells and p16 promoter is methylated by smoke (Kim et al, 2001). The components of tobacco smoke might affect D40 expression by inducing mutations of D40 promoter DNA or changes of DNA methylation and histone acetylation status. As methylation of promoter DNA leads to transcriptional repression of the genes in general, D40 promoter DNA is probably 
not directly methylated by agents in smoke. Nucleosome histones in D40 promoter may be acetlylated by chemicals in smoke. Transcriptional repressor or activator that binds to the D40 promoter might be inactivated or activated, respectively, by mutation of their genes or nucleosome modification of their promoters. The molecular basis of how mutagenic chemicals in tobacco smoke cause both increases and decreases in gene expression during carcinogenesis should be revealed by future studies.

As CT antigen could represent the ideal immuno-therapeutic agent against cancer, extensive studies have identified dozens of genes in the CT family. In contrast, very few studies have revealed their physiological functions or clinico-pathological characteristics of their expressions. The above information could be quite important for characterising the CT genes and when considering the treatment of cancer patients with immunotherapy. As the carboxy terminal region of D40/AF15q14 protein contains a nuclear localisation signal, it may be a nuclear protein (Hayette et al, 2000). This protein may play important roles in gene regulation, such as at the levels of transcription and mRNA processing. As D40/AF15q14 does not contain other conserved amino acid motifs or domains with known functions, this protein might have a veiled function in gene regulation. As individual tumour express different CT antigens, time is required to determine which CT antigen is expressed in the tumour before the patient is treated with immuno-therapy. If this could be predicted from the clinico-pathological findings of the tumours and determined quickly, treatment would be facilitated.

\section{REFERENCES}

Bearhs OH, Henson DE, Hutter RVP, Kennedy BJ (1992) Lung. In Manual for Staging of Cancer, pp 115-122. Chicago

Belinsky SA, Nikula KJ, Baylin SB, Issa JP (1996) Increased cytosine DNAmethyltransferase activity is target-cell- specific and an early event in lung cancer. Proc Natl Acad Sci USA 93: 4045-4050

Bishop JM (1987) The molecular genetics of cancer. Science 235: 305-311

Bloom W, Fawcett DW (1994) A Textbook of Histology. Philadelphia: WB Saunders Company

Boon T, Coulie PG, Van den Eynde B (1997) Tumor antigens recognized by T cells. Immunol Today 18: $267-268$

Brinkmann U, Vasmatzis G, Lee B, Yerushalmi N, Essand M, Pastan I (1998) PAGE-1, an X chromosome-linked GAGE-like gene that is expressed in normal and neoplastic prostate, testis, and uterus. Proc Natl Acad Sci USA 95: $10757-10762$

Chen Y-T, Old LJ (1999) Cancer-Testis antigens: targets for cancer immunotherapy. Cancer J Sci Am 5: 16-17

Chien CT, Bartel PL, Sternglanz R, Fields S (1991) The two-hybrid system: a method to identify and clone genes for proteins that interact with a protein of interest. Proc Natl Acad Sci USA 88: 9578-9582

Chomczynski P, Sacchi N (1987) Single-step method of RNA isolation by acid guanidinium thiocyanate-phenol-chloroform extraction. Anal Biochem 162: $156-159$

De Smet C, Martelange V, Lucas S, Brasseur F, Lurquin C, Boon T (1997) Identification of human testis-specific transcripts and analysis of their expression in tumor cells. Biochem Biophys Res Comm 241: 653-657

Denissenko MF, Pao A, Tang M, Pfeifer GP (1996) Preferential formation of benzo[a]pyrene adducts at lung cancer mutational hotspots in P53. Science 274: $430-432$

Dimartino JF, Cleary ML (1999) MLL rearrangements in haematological malignancies: lessons from clinical and biological studies. Br J Haematol 106: $614-626$

Dosaka-Akita H, Hommura F, Fujita H, Kinoshita I, Nishi M, Morikawa T, Katoh H, Kawakami Y, Kuzumaki N (1998) Frequent loss of gelsolin expression in non-small cell lung cancers of heavy smokers. Cancer Res 58: $322-327$

Durfee T, Becherer K, Chen PL, Yeh SH, Yang Y, Kilburn AE, Lee WH, Elledge SJ (1993) The retinoblastoma protein associates with the protein phosphatase type 1 catalytic subunit. Genes Dev 7: 555-569

Fields S, Song O (1989) A novel genetic system to detect protein-protein Interactions. Nature 340: $245-246$
In summary, this study revealed that D40/AF15q14 is a new gene in cancer/testis family and its expression is significantly related to smoking. This study would contribute to further understandings of the mechanism of aberrant CT gene expression in tumours and to the application of CT genes for immunotherapy against cancer.

\section{ACKNOWLEDGEMENTS}

We thank Dr K Iwabuchi, Dr S Fields, Dr S Elledge, Dr A Nishimune, Dr M Lamphier, Dr R Sternglanz and Dr K Matsubara for information, instruction, plasmids cDNA library for two-hybrid system, Dr S Kudo for cDNA library, Dr R Kageyama for plasmid, Dr M Tada, Dr N Shinohara for tumour samples and/or RNAs, and Dr M Hosokawa, Dr T Moriuchi, Dr Y Iida, Dr H Ikeda, Dr H Sahara, Dr Rong, Dr N Satoh, and H Fujita and the members of Division of Cancer Gene Regulation, Institute for Genetic Medicine, Hokkaido University for valuable discussions. This study was supported by grant-in-aids from the Ministry of Education, Science, Culture, and Sport of Japan, from Ono Cancer Foundation, from Hokkaido Foundation for the Promotion of Scientific and Industrial Technology (Hokscitec), from Foundation for promotion of Cancer Research in Japan and from Osaka Cancer Research Foundation.

Frohman MA, Dush MK, Martin GR (1988) Rapid production of full-length cDNAs from rare transcript: Amplification using a single gene-specific oligonucleotide primer. Proc Natl Acad Sci USA 85: 8998-9002

Hayette S, Tigaud I, Vanier A, Martel S, Corbo L, Charrin C, Beillard E, Deleage G, Magaud JP, Rimokh R (2000) AF15q14, a novel partner gene fused to the MLL gene in an acute myeloid leukaemia with a $\mathrm{t}(11 ; 15)(\mathrm{q} 23 ; \mathrm{q} 14)$. Oncogene 19: 4446-4450

Hernandez JM, Mecucci C, Beverloo HB, Selleri L, Wlodarska I, Stul M, Michaux L, Verhoef G, Van Orshoven A, Cassiman JJ (1995) Translocation $(11 ; 15)(\mathrm{q} 23 ; \mathrm{q} 14)$ in three patients with acute non-lymphoblastic leukemia (ANLL): clinical, cytogenetic and molecular studies. Leukemia 9: 1162 1166

Hunger SP, Tkachuk DC, Amylon MD, Link MP, Carroll AJ, Welborn JL, Willman CL, Cleary ML (1993) HRX involvement in de novo and secondary leukemias with diverse chromosome 11q23 abnormalities. Blood 81: $3197-3203$

Kim DH, Nelson HH, Wiencke JK, Zheng S, Christiani DC, Wain JC, Mark EJ, Kelsey KT (2001) p16(INK4a) and histology-specific methylation of $\mathrm{CpG}$ islands by exposure to tobacco smoke in non-small cell lung cancer. Cancer Res 61: 3419-3424

Kageyama R, Pastan I (1989) Molecular cloning and characterization of a human DNA binding factor that represses transcription. Cell 59: 815-825

Mehta CR, Patel NR (1983) A network algorithm for performing Fisher's exact test in $\mathrm{r} \times \mathrm{c}$ contingency tables. $J$ Am Stat Assoc 78: 427-434

Reed AL, Yamazaki H, Kaufman JD, Rubinstein Y, Murphy B, Jhonson AC (1998) Molecular cloning and characterization of a transcription regulator with homology to GC-bining factor. J Biol Chem 273: 21594-21602

Ruggeri B, DiRado M, Zhang SY, Bauer B, Goodrow T, Klein-Szanto AJ (1993) Benzo[a]pyrene-induced murine skin tumors exhibit frequent and characteristic G to T mutations in the p53 gene. Proc Natl Acad Sci USA 90: $1013-1017$

Sahin U, Tureci O, Schmitt H, Cochlovius B, Johannes T, Schmits R, Stenner F, Luo G, Schobert I, Pfreundschuh M (1995) Human neoplasms elicit multiple specific immune responses in the autologous host. Proc Natl Acad Sci USA 92: $11810-11813$

Sambrook J, Fritsch EF, Maniatis T (1989) Molecular Cloning: A Laboratory Manual, Second Edition. Cold Spring Harbor NY: Cold Spring Harbor Laboratory Press

Sanger F, Nicklen S, Coulson AR (1977) DNA sequencing with chain-terminating inhibitors. Proc Natl Acad Sci USA 74: 54-63 
Suzuki K, Tsujitani S, Konishi I, Yamaguchi Y, Hirooka Y, Kaibara N (1999) Expression of MAGE genes and survival in patients with hepatocellular carcinoma. Int J Oncol, 15: 1227-1222

Takimoto M (1999) Twenty-fifth Symposium of Nucleic Acid Chemistry. Nucleic Acid Symposium series, Vol 42, pp 69-70. Oxford: Oxford University Press

Takimoto M, Mao P, Wei G, Yamazaki H, Miura T, Johnson AC, Kuzumaki N (1999) Molecular analysis of the GCF gene identifies revisions to the cDNA and amino acid sequences. Biochim Biophys Acta 1447: 125-131
Thirman MJ, Levitan DA, Kobayashi H, Simon MC, Rowley JD (1994) Cloning of ELL, a gene that fuses to MLL in a $\mathrm{t}(11 ; 19)(\mathrm{q} 23 ; \mathrm{p} 13.1)$ in acute myeloid leukemia. Proc Natl Acad Sci USA 91: 12110-12114

Van der Bruggen P, Traversari C, Chomez P, Lurquin C, De Plaen E, Van den Eynde B, Knuth A, Boon T (1991) A gene encoding an antigen recognized by cytolytic $\mathrm{T}$ lymphocytes on a human melanoma. Science 254: $1643-$ 1647

WHO (1982) The World Health Organization histological typing of lung tumors: second edition. Am J Clin Pathol 77: 123-136 